\title{
Inhibition of Myeloperoxidase by N-Acetyl Lysyltyrosylcysteine Amide Reduces Oxidative Stress-Mediated Inflammation, Neuronal Damage, and Neural Stem Cell Injury in a Murine Model of Stroke
}

\author{
Guoliang Yu, Ye Liang, ${ }^{1}$ Shikan Zheng, ${ }^{2}$ and Hao Zhang \\ Division of Pediatric Surgery, Department of Surgery, Medical College of Wisconsin, Milwaukee, Wisconsin \\ Received October 13, 2017; accepted December 7, 2017
}

\begin{abstract}
Recent studies suggest that myeloperoxidase (MPO)-dependent oxidative stress plays a significant role in brain injury in stroke patients. We previously showed that $\mathrm{N}$-acetyl lysyltyrosylcysteine amide (KYC), a novel MPO inhibitor, significantly decreased infarct size, blood-brain barrier leakage, infiltration of myeloid cells, loss of neurons, and apoptosis in the brains of middle cerebral artery occlusion (MCAO) mice. Inhibition of MPO also noticeably reduced neurologic severity scores of MCAO mice. Thus, our data support the idea that MPO-dependent oxidative stress plays a detrimental role in tissue injury in ischemic stroke. However, the mechanisms of MPO-induced injury in stroke are still largely unknown. Here, we present new evidence showing that KYC treatment greatly reduced inflammation by decreasing the number of proinflammatory M1 microglial cells and N1
\end{abstract}

neutrophils in the brains of MCAO mice. KYC also markedly reduced the expression of high-mobility group box 1 , receptor for advanced glycation end products, and nuclear factor- $\kappa \mathrm{B}$ in the brains of MCAO mice. Both neurons and neural stem cells (NSCs) were oxidatively injured by MPO-dependent oxidative stress in MCAO mice. Inhibiting MPO-dependent oxidative stress with KYC significantly reduced oxidative injury and apoptosis in neurons and NSCs. KYC treatment also protected transplanted exogenous NSCs in the brains of MCAO mice. Thus, our studies suggest that MPO-dependent oxidative stress directly injures brain tissues by oxidizing neurons and NSCs and increasing inflammation during stroke. Inhibition of MPO activity with KYC preserves neuronal function and helps the brain recover from injury after stroke.

\section{Introduction}

During ischemic stroke, ischemia/reperfusion (I/R) initiates a series of deleterious events that severely injure the brain (Nour et al., 2013). One such deleterious event that is induced by $\mathrm{I} / \mathrm{R}$ is the upsurge of oxidative stress (El Kossi and Zakhary, 2000; Allen and Bayraktutan, 2009; Chen et al., 2011; Manzanero et al., 2013). Extensive evidence has suggested that the increase in oxidative stress is a critical factor for brain injury after stroke. The products of protein oxidation, lipid peroxidation, and DNA oxidation are increased in animal models of stroke (Fukuyama et al., 1998; El Kossi and Zakhary, 2000; Nagayama et al., 2000; Chen et al., 2009). Various oxidation biomarkers have also been detected in stroke patients (Re et al., 1997; Bolokadze et al., 2004; Isobe et al., 2009). These studies strongly support the idea that

\footnotetext{
${ }^{1}$ Current affiliation: Program in Bioinformatics, Zanvyl Krieger School of Arts and Sciences, Johns Hopkins University, Baltimore, Maryland.

${ }^{2}$ Current affiliation: Department of Mathematics, Statistics and Computer Science, Marquette University, Milwaukee, Wisconsin.

https://doi.org/10.1124/jpet.117.245688.
}

oxidative stress plays a key role in tissue injury during stroke. Accordingly, oxidative stress has been proposed as a drug target for treating stroke patients (Allen and Bayraktutan, 2009; Davis and Pennypacker, 2016).

Myeloperoxidase (MPO) is a highly versatile oxidative enzyme that is capable of generating potent oxidative stress in vivo. After activation with $\mathrm{H}_{2} \mathrm{O}_{2}$, MPO generates a wide variety of oxidants (Arnhold and Flemmig, 2010). For example, MPO can oxidize chloride and nitrite to hypochlorous acid and nitrogen dioxide radical, respectively. Hypochlorous acid and nitrogen dioxide radical oxidize tyrosine in proteins to chlorotyrosine (ClTyr) and nitrotyrosine ( $\left.\mathrm{NO}_{2} \mathrm{Tyr}\right)$. MPOgenerated oxidants are much more potent for oxidizing biomolecules and inducing cellular injury than $\mathrm{O}_{2}^{-\bullet}$ and $\mathrm{H}_{2} \mathrm{O}_{2}$ (Davies et al., 2008; van der Veen et al., 2009). Several studies reported that serum MPO levels are elevated in acute stroke patients (Re et al., 1997; Cojocaru et al., 2010; Dominguez et al., 2010; Shoamanesh et al., 2015). Increased serum MPO levels in stroke patients have been associated with white matter hyperintensity, an indicator of stroke severity that can be assessed from brain magnetic resonance

ABBREVIATIONS: CITyr, chlorotyrosine; DAPI, 4',6-diamidino-2-phenylindole; DCX, doublecortin; GFP, green fluorescent protein; HMGB1, highmobility group box $1 ; \mathrm{l} / \mathrm{R}$, ischemia/reperfusion; KO, knockout; KYC, $N$-acetyl lysyltyrosylcysteine amide; MCAO, middle cerebral artery occlusion; MPO, myeloperoxidase; NF- $\kappa$ B, nuclear factor $-\kappa \mathrm{B} ; \mathrm{NIH}$, National Institutes of Health; $\mathrm{NO}_{2}$ Tyr, nitrotyrosine; NSC, neural stem cell; PBS, phosphatebuffered saline; RAGE, receptor for advanced glycation end products; SOX2, sex-determining region Y-box 2; TUNEL, terminal deoxynucleotidyl transferase-mediated dUTP-biotin nick-end labeling. 
imaging scans (Wright et al., 2009). MPO levels are routinely used to assess neutrophil infiltration in brain tissue, and as a biomarker for diagnosis and prognosis of stroke (Barone et al., 1995; Weston et al., 2007; Breckwoldt et al., 2008; Chalouhi et al., 2014). Recent studies have shown that inhibition of MPO activity with specific inhibitors reduced infarct size and neuronal deficit in MCAO mice (Forghani et al., 2015; Yu et al., 2016), suggesting that MPO-dependent oxidative stress is associated with brain injury in stroke.

Recently, we treated a murine middle cerebral artery occlusion (MCAO) model of stroke with $N$-acetyl lysyltyrosylcysteine amide (KYC), a specific MPO inhibitor (Zhang et al., 2013a). We showed that KYC treatment inhibited MPO activity and reduced MPO protein in the brains of MCAO mice (Yu et al., 2016). KYC treatment significantly decreased neurologic severity scores, infarct size, blood-brain barrier leakage, infiltration of myeloid cells, loss of neurons, and apoptosis in the brains of MCAO mice. Although the data from our group and another group (Forghani et al., 2015; Yu et al., 2016) strongly suggested that MPO-dependent oxidative stress plays a detrimental role in tissue injury in stroke, the detailed mechanisms of MPO-mediated injury in stroke are still largely unknown.

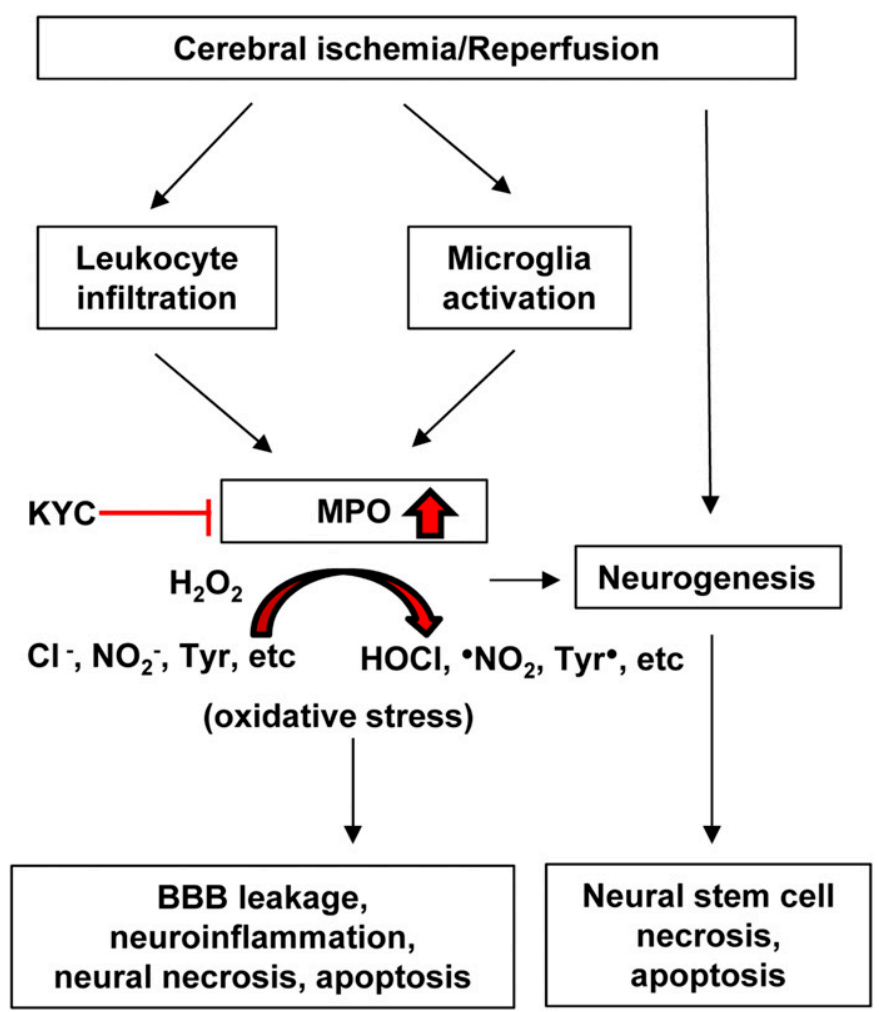

Scheme 1. MPO-dependent oxidation induced neural injury in stroke. MPO is rapidly released from leukocytes and microglia in brains of mice after cerebral ischemia/reperfusion. After activation with $\mathrm{H}_{2} \mathrm{O}_{2}$, MPO oxidizes chloride $\left(\mathrm{Cl}^{-}\right)$, nitrite $\left(\mathrm{NO}_{2}^{-}\right)$, tyrosine $(\mathrm{Tyr})$, etc. to potent oxidants, hypochlorous acid ( $\mathrm{HOCl})$, nitrogen dioxide $\left(\mathrm{NO}_{2}\right)$, tyrosyl radical (Tyr $\left.{ }^{\bullet}\right)$, etc., respectively. These free radicals and oxidants are more potent than $\mathrm{H}_{2} \mathrm{O}_{2}$ for oxidizing biomolecules. MPO-dependent oxidative stress induces bloodbrain barrier leakage (BB leakage) and increases neuroinflammation, and MPO activity causes both neuron and neural stem cell death in the brains after stroke. Inhibition of KYC specifically by specific MPO inhibitors, such as KYC, protects the brain from MPO-mediated oxidative-induced injury after stroke.
Because inhibition of MPO-dependent oxidative stress reduced overall oxidative injury and improved neurologic function in MCAO mice, we hypothesized that MPO-dependent oxidative stress damages both neurons and neural stem cells, which causes the loss of neurologic function in MCAO mice. Moreover, MPO-dependent oxidative injury further increases inflammation in MCAO mice and induces additional injury (Scheme 1). Here, we present data showing that inhibition of MPO activity in MCAO mice indeed markedly decreased the number of proinflammatory M1 microglial cells and N1 neutrophils. KYC also increased neuroregeneration and reduced oxidative injury of neurons and neural stem cells (NSCs) in MCAO mice. Our studies suggest that MPOdependent oxidative stress is a key mediator for increasing inflammation and oxidative injury in stroke. Inhibition of MPO activity globally reduces both inflammation and oxidative injury in brain tissue, which helps the brain to preserve neuronal function and recover from injury after stroke.

\section{Materials and Methods}

Animal. Male C57BL/6J mice (8-10 weeks) and MPO-knockout (MPO-KO) mice (8-10 weeks) were purchased from Jackson Laboratory (Bar Harbor, ME) and housed in the Medical College of Wisconsin with a 12-hour light/dark cycle, and were allowed free access to food and water. All animal procedures were approved by the Institutional Animal Care and Use Committee following the guide for the care and use of animals by the U.S. National Institutes of Health.

Model of Focal Cerebral Ischemia. Male mice were anesthetized with $2 \%$ isoflurane. A rectal temperature probe was inserted to monitor and maintain a constant animal core temperature of $37^{\circ} \mathrm{C} \pm$ $0.5^{\circ} \mathrm{C}$ using a temperature controller (TC-1000; CWE INC, Ardmore, PA). Transient focal cerebral ischemia was induced by MCAO as previously described (Yu et al., 2016). In brief, a 6-0 nylon monofilament suture coated with silicon-rubber (Doccol, Sharon, MA) was inserted into the left internal carotid artery and advanced approximately $10 \mathrm{~mm}$ distal to the carotid bifurcation to occlude the origin of the middle cerebral artery. The thread was carefully withdrawn 30 minutes after MCAO to induce I/R injury. In sham-operation animals, the same procedure was performed without inserting the intraluminal filament. Mice were divided randomly into three groups: 1) sham group, 2) MCAO + phosphate-buffered saline (MCAO+PBS), and 3) $\mathrm{MCAO}+\mathrm{KYC}$.

Neurobehavioral Testing. Neurologic severity scores were determined by a number of tests to assess motor function, sensory function, and reflex (Li et al., 2000). In brief, after raising the mouse by the tail, flexion of forelimb, head movement $>10^{\circ}$ to the vertical axis, and circling toward the paralytic side were assessed. Three more tests were performed by placing the mouse on the floor to assess abnormal gait, circling toward the paralytic side, and frequency of falling over. Finally, pinna reflex (a head shake upon touching the auditory meatus) and visual placement test (stretching of forelimbs to meet an approaching object) were also evaluated. Each test was scored as 0 for normal and 1 for abnormal, yielding a summed injury score from 0 to 8 . Mice were tested for neurobehavioral deficits daily and by a single "blind" investigator, who had no knowledge of assignment of treatment groups.

Drug Administration. Groups of mice were administered either PBS or KYC (10.0 mg/kg per day; Biomatik, Wilmington, DE) intraperitoneally starting from 1 hour after MCAO. Mice were treated daily for 3, 7, or 21 days after MCAO. The treatments started 2 days after MCAO in one experiment to determine the therapeutic window. The dosage of KYC was determined according to the pharmacokinetics of KYC in plasma we previously published (Zhang et al., 2013b) in our studies on the effects of KYC in a murine EAE experimental autoimmune encephalomyelitis model of multiple sclerosis (Zhang 
et al., 2015) and in our studies on a MCAO model of stroke (Yu et al., 2016).

Histopathology. Three, 7, and 21 days after ischemia, mice were anesthetized and perfused transcardially with $4 \%$ paraformaldehyde after prewashing with $0.01 \mathrm{M}$ PBS. Brain tissues were then fixed in $4 \%$ paraformaldehyde overnight and were transferred to $20 \%$ and $30 \%$ sucrose for 1 day, respectively. Whole-brain images were captured by an Olympus SZX16 Stereo Microscope (Olympus America Inc., Center Valley, PA). Coronal brain sections $(10 \mu \mathrm{m})$ from the frontal lobe to brainstem were cut by cryomicrotomy (CM1900; Leica, Wetzlar, Germany) and mounted onto precleaned slides for immunohistochemistry. Brain atrophy of mice 21 days after MCAO was assessed according to a previous report (Hurn and Macrae, 2000) and expressed as the percentage of the decrease of brain surface area of the ischemic hemisphere compared with the nonischemic hemisphere using ImageJ [National Institutes of Health (NIH), Bethesda, MD].

Immunohistochemistry. The following protocol was used to determine neutrophil accumulation, microglia/macrophage activation, high-mobility group box 1 (HMGB1)-receptor for advanced glycation end products (RAGE)-nuclear factor- $\kappa$ B (NF- $\kappa$ B) p50 pathway expression, MPO oxidant production, NSCs, and neuron density in the ischemic core or penumbra of the brain cortex. Frozen tissue sections $(10 \mu \mathrm{m})$ were incubated with $5 \%$ goat or donkey serum in $0.01 \mathrm{M}$ PBS for 1 hour. The sections were then incubated with rat antiNIMP-R14 (1:200; Abcam, Cambridge, MA), rabbit anti-CD206 (sc-48758, 1:50; Santa Cruz, Dallas, TX), goat anti-Iba1 (1:200; Abcam), rat antiCD16 (553142, 1:100; BD Biosciences, San Jose, CA), rabbit antiHMGB1 (ab18256, 1:500; Abcam), goat anti-RAGE (sc-8229, 1:50; Santa Cruz), rabbit anti-NF-кB p50 (sc-114, 1:50; Santa Cruz), rabbit anti-Arg 1 (sc-271430, 1:50; Santa Cruz), rabbit anti-ClTyr (HP5002, 1:50; Hycult Biotech, Plymouth Meeting, PA), mouse anti-NO $\mathrm{N}_{2} \mathrm{Tyr}$ (SC-65384, 1:50; Santa Cruz), mouse anti-neuronal nuclei (1:200; Abcam), goat anti-sex-determining region Y-box 2 (SOX2) (SC-17320, 1:50; Santa Cruz), goat anti-Nestin (SC-21248, 1:50; Santa Cruz), mouse anti-Doublecortin (SC-271390, 1:50; Santa Cruz), rabbit antiKi76 (12202S, 1:100; Cell Signaling, Danvers, MA), and anttransmembrane protein 119 (Tmem119) (SC-244341, 1:50; Santa Cruz) antibodies at $4^{\circ} \mathrm{C}$ overnight. Then, sections were rinsed and incubated with secondary antibodies conjugated with Alexa Fluor 488 or 568 (1:800; Life Technologies, Carlsbad, CA) for 1 hour. Finally, the sections were counterstained with 4',6-diamidino-2-phenylindole (DAPI) to visualize cell nuclei. Comparable brain sections in MCAO mice from PBS and KYC groups were selected for analysis. Images of three areas in the cortex from three predetermined corticostriatal sections with the largest infarct profiles were captured at random using a fluorescence microscope (DP71; Olympus America Inc.). The immunostained positive cells were counted in each area and calculated as counts $/ \mathrm{mm}^{2}$ by a single "blind" investigator, who had no knowledge of the assignment of treatment groups, using NIH ImageJ.

Terminal Deoxynucleotidyl Transferase-Mediated dUTPBiotin Nick-End Labeling Assay. The terminal deoxynucleotidyl transferase-mediated dUTP-biotin nick-end labeling (TUNEL) assay was used to identify apoptotic cells with nuclear DNA fragmentation in brain ischemic core areas. Staining was performed according to the manufacturer's instructions (Click-iT Plus TUNEL Kit; Thermo Fisher, Waltham, MA). In brief, brain sections adjacent to those used for immunohistochemistry were incubated with proteinase K (15 minutes, RT room temperature) and then rinsed with PBS. After incubation with Terminal deoxynucleotidyl transferase reaction buffer (10 minutes) and Terminal deoxynucleotidyl transferase reaction mixture ( 1 hour at $37^{\circ} \mathrm{C}$ ), sections were washed and incubated with Click-iT Plus reaction cocktail containing Alexa Fluor 488 (30 minutes at $37^{\circ} \mathrm{C}$ ). Finally, sections were counterstained with DAPI.

Western Blotting. Three days after ischemia, anesthetized mice were perfused with PBS. Then, brain tissue was collected and stored at $-80^{\circ} \mathrm{C}$. Brain tissue proteins were extracted into radioimmunoprecipitation assay buffer containing Protease Inhibitor Cocktail and EDTA (1:100, v/v; Thermo Fisher). Extracted proteins were separated by SDS-PAGE and transferred to nitrocellulose membranes. Membranes were blocked with 5\% nonfat dry milk in Tris-buffered saline/Tween 20 buffer and subsequently incubated with rabbit anti$\beta$-catenin or rabbit anti-Frizzled receptor antibodies (1:200; Santa Cruz), or mouse anti- $\beta$-actin (1:1000; Sigma, St. Louis, MO) overnight at $4^{\circ} \mathrm{C}$ on a rocking platform. After washing, the membranes were incubated with peroxidase-conjugated anti-rabbit IgG (1:5000; Jackson Laboratory) for 1 hour, and protein bands were detected by ECL (Life Technologies). Density analyses were performed using NIH ImageJ.

In Situ Hybridization. The probe for detection of MPO mRNA was custom designed and synthesized by Exiqon Inc. (Woburn, MA). The sequence of the probe is 5DigN/TCTATGAAGAAGGAGGGGTGGA/3DigN. The in situ hybridization was performed according to the manufacturer's instructions (miRCURY LNA ISH Optimization Kit; Exiqon). In brief, brain sections were digested with proteinase $\mathrm{K}$, washed with PBS, and dehydrated. Each section was incubated with $100 \mu \mathrm{l}$ of hybridization solution containing MPO probes or scrambled control probes in humidified chambers at $59^{\circ} \mathrm{C}$ for 1 hour. Then, the sections were washed through graded saline-sodium citrate buffers and incubated in blocking solution at room temperature for 1 hour. Hybridized MPO probes were detected by incubating brain sections with mouse anti-Digoxigenin IgG (1:1000; Sigma) at $4^{\circ} \mathrm{C}$ overnight. After washing with PBS again, the sections were incubated with goatanti-mouse IgG conjugated with Alexa 488 (1:800; Life technologies) at room temperature for 1 hour. Finally, sections were washed with PBS and covered with antifade mounting medium containing DAPI.

NSC Culture and Transplantation. NSCs were isolated from the brain cortex of postnatal day 1 Green Fluorescent Protein transgenic C57BL/6J mice (unknown sex) and maintained using methods described previously (Donega et al., 2014). In brief, whole brains were surgically removed from GFP transgenic mice at postnatal day 1 . The brain cortex was dissected, cut into small pieces, and digested with a Papain Dissociation System Kit (Worthington Biochemical, Lakewood, NJ) for 30 minutes at $37^{\circ} \mathrm{C}$. The cell suspension was centrifuged, and the pelleted NSC cells were resuspended in NeuroCult Mouse Proliferation Medium (Stemcell Techno, Vancouver, CA) supplemented with basic fibroblast growth factor $(10 \mathrm{ng} / \mathrm{ml})$, epidermal growth factor $(20 \mathrm{ng} / \mathrm{ml}$ ), and antibiotics (penicillin/streptomycin). Then, NSC suspension was transferred to T75 flasks, and NSCs were cultured at $37^{\circ} \mathrm{C}$ in a humidified $5 \% \mathrm{CO}_{2}$ incubator. The cultures were refilled with $0.5 \mathrm{ml}$ of medium every day. After 5-7 days, neurospheres were formed. The medium containing neurospheres was collected and centrifuged again. Neurospheres were resuspended in culture medium and dissociated by $0.05 \%$ Trypsin into a single cell suspension. The neurospheres were subcultured for 4-5-day intervals for at least five passages before being used for NSC transplantation. For NSC transplantation, neurospheres were collected and dissociated into a single cell suspension as earlier. On day 1 after MCAO, $0.2 \mathrm{ml}$ of cell suspension $\left(2.5 \times 10^{6}\right.$ cells $\left./ \mathrm{ml}\right)$ was administered via the retro-orbital venous sinus in mice.

Statistical Analysis. Data were expressed as the means \pm S.E.M. Neurologic scores were analyzed by repeat-measure two-way analysis of variance. Other statistical analyses were performed using nonparametric Mann-Whitney test, Student's $t$ test, or one-way analysis of variance with the appropriate post-hoc test for multiple comparisons. A $P$ value of $<0.05$ was considered statistically significant.

\section{Results}

KYC, a Specific MPO Inhibitor, Reduced Ischemia/ Reperfusion Injuries in a Murine Model of Stroke. In our recent publication (Yu et al., 2016), KYC treatment significantly reduced neurologic severity scores of MCAO mice compared with PBS-treated MCAO mice 7 days after MCAO. To determine if inhibition of MPO activity protects neuronal function of MCAO mice for a longer period of time, we extended 
A

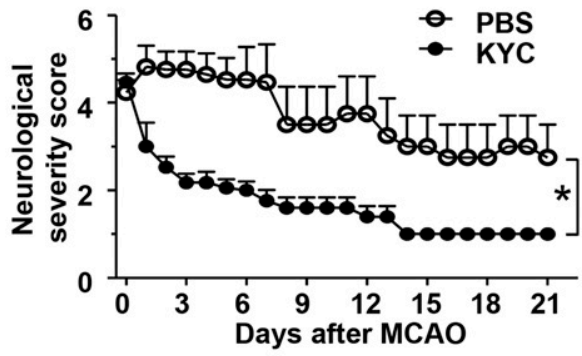

B

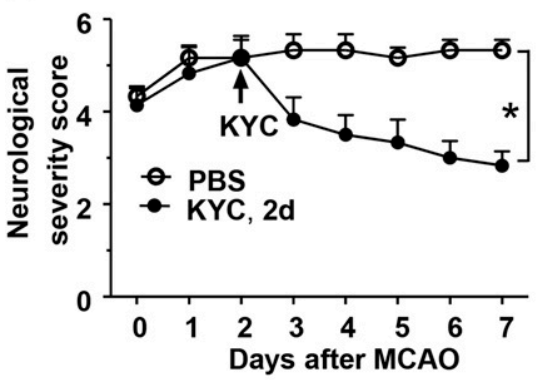

D

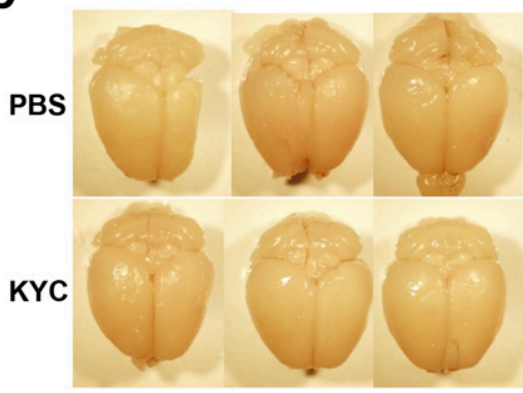

C

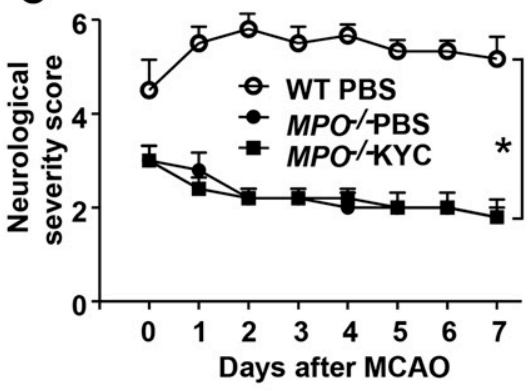

$\mathbf{E}$

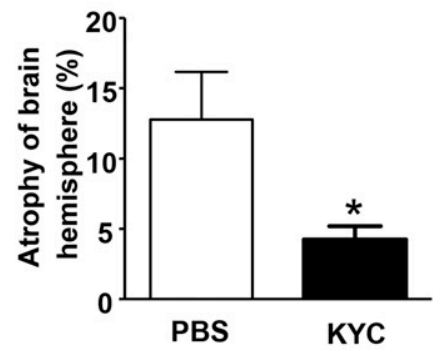

Fig. 1. Effect of KYC on neurologic severity scores and brain atrophy of MCAO mice. The preparation of MCAO mice and the assessment of neurologic severity scores are described in Materials and Methods. (A) The effect of $\mathrm{KYC}$ on neurologic severity scores of mice during 21 days after MCAO. Daily KYC administration $(10 \mathrm{mg} / \mathrm{kg} / \mathrm{day}$, i.p.) was started 1 hour after reperfusion $(n=5$ for PBS and 5 for KYC) for 21 days. (B) The effect of delayed KYC treatment on the neurologic severity scores of MCAO mice. KYC treatment (10 mg/kg/day, i.p.) was started 48 hours after reperfusion ( $n=6 /$ group). (C) The effect of $\mathrm{KYC}$ on the neurologic severity scores of MPO-KO MCAO mice ( $n=5 /$ group). Daily KYC administration $(10 \mathrm{mg} / \mathrm{kg} / \mathrm{day}$, i.p.) was started 1 hour after reperfusion. Data for the neurologic severity scores are presented as means \pm S.E.M. Statistical analyses: repeated-measure two-way analysis of variance. ${ }^{*} P<0.05$. (D) Gross photographs of whole brains of mice 3 weeks after MCAO. (E) The assessment of brain atrophy. The percentage of the decrease of brain surface area of the ischemic hemisphere [the right side of brain in (D)] compared with the nonischemic hemisphere [the left side of brain in (D)] was determined according to a previous publication (Becker et al., 2005) $(n=5$ /group, $* P<0.05$, KYC vs. PBS, nonparametric Mann-Whitney test). our observation of neurologic severity scores to 21 days after MCAO. Figure 1A shows that the average scores of PBS-treated mice slowly decreased to around three at the end of the 21-day period after MCAO. In contrast, the average scores of KYCtreated mice decreased rapidly and significantly after MCAO compared with the PBS group ( $n=5, P<0.05)$. Two weeks after MCAO, the scores of every mouse decreased to 1 . To determine if KYC has a sufficiently wide therapeutic window, we started KYC treatment 48 hour after reperfusion (Fig. 1B). In Fig. 1B, we show that KYC administrated 2 days after MCAO still rapidly decreased the neurologic severity scores ( $n=5, P<0.05$, KYC vs. PBS). To further confirm KYC's specificity in vivo, we treated MCAO MPO-KO mice with KYC (Fig. 1C). MCAO MPO-KO mice had lower disease scores than MCAO wild-type mice ( $n=5, P<0.05)$ and did not respond to KYC treatment, indicating that KYC specifically targets MPO in MCAO mice. Finally, gross photographs of whole brains of MCAO mice showed the atrophy in the ischemic hemispheres at the end of a 21-day experiment (Fig. 1D). Further analysis of the decrease of brain surface area of the ischemic hemisphere compared with the nonischemic hemisphere (Fig. 1E) showed that KYC treatment significantly reduced atrophy in the brains of MCAO mice $(n=5, P<0.05)$.

KYC Treatment Decreased the Number of M1 Microglial Cells and N1 Neutrophils in the Brains of MCAO Mice. In our previous report, we showed that inhibition of MPO activity noticeably reduced $\mathrm{Iba}^{+}$cells (Yu et al., 2016). Because Iba1 is a marker for both activated macrophage and microglia, we colocalized $\mathrm{Iba}^{+}$in the brain sections of MCAO mice with Tmem119, a specific marker for microglia (Bennett et al., 2016) (Fig. 2A). Our results indicated that $>95 \%(n=5)$ of $\mathrm{Iba}^{+}$cells in the brain cortex ischemic core of MCAO mice were microglial cells. KYC treatment significantly reduced microglia after MCAO (Fig. $2 \mathrm{~B}, P<0.01$ ). We also confirmed that $\mathrm{Iba}^{+}$cells expressed a high level of MPO mRNA detected by in situ hybridization (Fig. 2C) in the brain cortex ischemic core of PBS-treated MCAO mice, suggesting that microglia are one of the major sources for MPO expression. Recent studies showed that microglia polarization may play a significant role in the pathophysiology of stroke (Pan et al., 2011). We colocalized $\mathrm{Iba1}^{+}$cells with CD16, a marker for M1 polarization (Fig. 2D). Our results revealed that most of the Iba1 ${ }^{+}$cells in the brain cortex ischemic core of PBS-treated MCAO mice were $\mathrm{CD} 16^{+}\left(96 \%\right.$ of total Iba1 ${ }^{+}$cells, $\left.n=5\right)$. KYC treatment significantly reduced $\mathrm{Iba}^{+} / \mathrm{CD} 16^{+}$cells $(n=5, P<0.05)$ (Fig. $2 \mathrm{E})$. On the other hand, only a few of the $\mathrm{Iba}^{+}$cells were arginase I (Arg1) positive, a marker for M2 polarization, in the brain cortex ischemic core of mice 3 days after MCAO (Fig. 2F). KYC did not make any notable change in M2 cells (Fig. 2G). We also investigated the impact of KYC treatment on the $\mathrm{N} 1 / \mathrm{N} 2$ polarization of neutrophils. Figure $2 \mathrm{H}$ shows the colocalization of NIMP-R14 ${ }^{+}$cells, a biomarker for neutrophils, with CD206, a marker for N2 neutrophils, in the brain cortex ischemic core of mice 3 days after MCAO. We found that the majority of neutrophils in the brains of MCAO mice were N1 neutrophils (NIMP-R14 $\left.{ }^{+} / \mathrm{CD} 206^{-}\right)$( $\sim 80 \%$ of total 

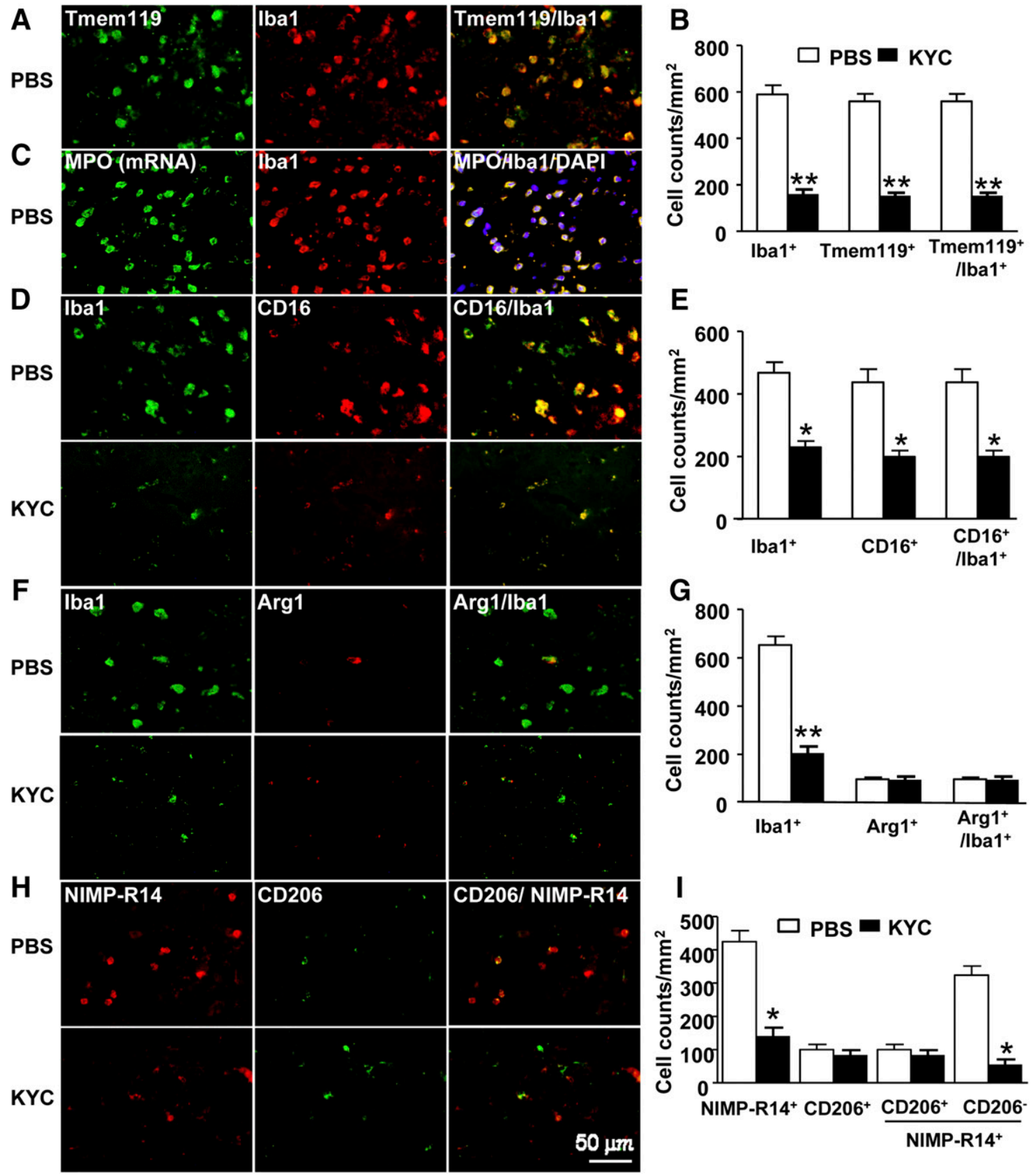

Fig. 2. Myeloid cells in the brain cortex ischemic core of mice 3 days after MCAO. (A) Images of expression of Tmem 119 in Iba1 ${ }^{+}$cells in PBS-treated MCAO mice. (B) Cell counts of Tmem $119^{+}$cells. (C) Images of expression of MPO mRNA in Iba1 $1^{+}$cells in PBS-treated MCAO mice. (D) Images of expression of CD16 in Iba $1^{+}$cells in both PBS- and KYC-treated mice. (E) Cell counts of CD $16^{+}$cells. (F) Images of expression of arginase I in Iba $1^{+}$cells. (G) Cell counts of arginase $\mathrm{I}^{+}$cells. (H) Images of expression of CD206 in neutrophils. (I) Cell counts of CD206 ${ }^{+}$cells. The images represent five per group. No microglia cells were detected in contralateral sides. Statistical analysis: ${ }^{*} P<0.05$; ${ }^{* *} P<0.01$, KYC vs. PBS, nonparametric Mann-Whitney test.

neutrophils), and KYC treatment significantly reduced the number of $\mathrm{N} 1$ neutrophils in brain sections $(n=5, P<0.05$; Fig. 2I). The number of N2 neutrophils (NIMP-R14 ${ }^{+} / \mathrm{CD}_{206}{ }^{+}$) was significantly less than N1 neutrophils in MCAO mice. Moreover, KYC treatment had no significant impact on the number of N2 neutrophils in MCAO mice.

KYC Reduced Inflammation in the Brains of MCAO Mice. Figure 3 shows that HMGB1, RAGE, and NF- $\kappa$ B p50 expression were each substantially upregulated in the brain cortex ischemic core of mice 3 days after MCAO. Moreover, HMGB1 translocated from the nucleus to cytoplasm (green) was found in the PBS group (Qiu et al., 2008), which indicated an increase of necrosis after MCAO. Additional NF- $\kappa \mathrm{B}$ p50 nuclear translocation (purple) also suggested that MCAO markedly activated the NF- $\kappa \mathrm{B}$ signaling pathway (Bowie and O'Neill, 2000). Compared with the PBS-treated group, KYC significantly reduced the level of HMGB1 $(n=5, P<0.01$; Fig. 3B), RAGE ( $n=5, P<0.01$; Fig. $3 \mathrm{D})$, and p50 $(n=5, P<0.05$; Fig. $3 \mathrm{~F}$ ) in the brain cortex ischemic core of MCAO mice. In addition, most of the HMGB1 was in the nucleus of cells (greenish blue) after KYC treatment. KYC also significantly reduced $\mathrm{TUNEL}^{+}$and $\mathrm{p} 53^{+}$cells (Yu et al., 2016), indicating 

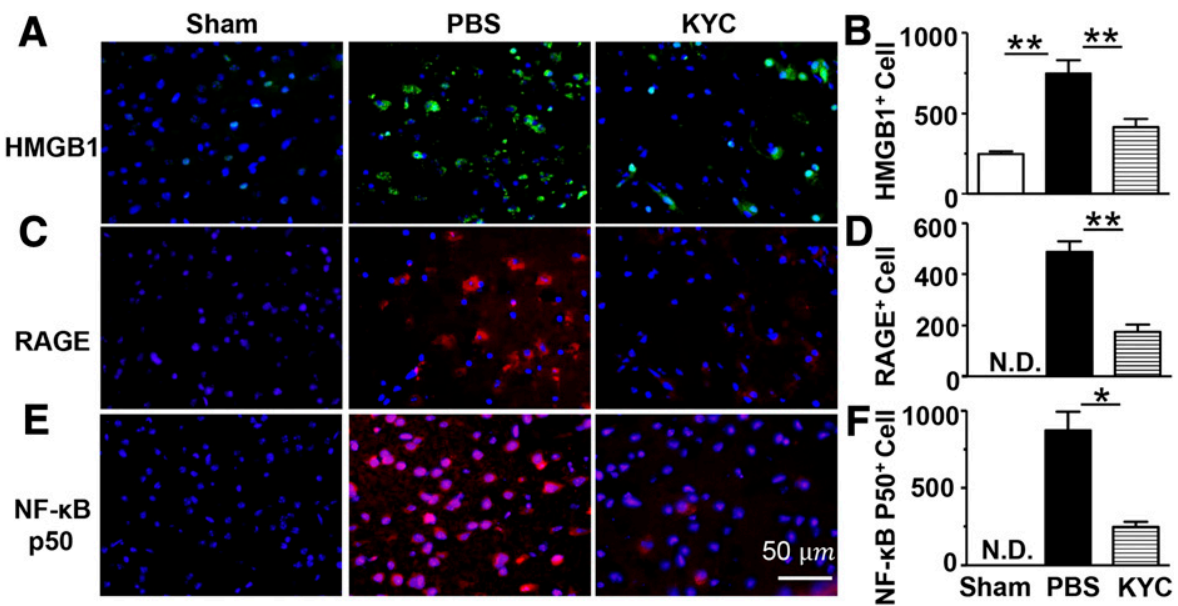

Fig. 3. Effects of KYC on the HMGB1/RAGE/NF- $\kappa$ B pathway in the cortex ischemic core of MCAO mice. Brain sections of MCAO mice treated with PBS or KYC (10 mg/kg/day, i.p.) for 3 days were stained for HMGB1 (green) (A) RAGE (red) (C), NF- $\kappa$ B p50 (red) (E), and DAPI (blue) ( $n=5$ /group). The graphs [HMGB1 (B), RAGE (D), and NF- $\kappa$ B p50 (F)] are means \pm S.E.M. of cell counts $\left(\right.$ cells $\left./ \mathrm{mm}^{2}\right)$. Statistical analyses: one-way analysis of variance with Bonferroni's test, $* P<0.05$; ${ }^{*} P<0.01$. N.D., none detected. Contralateral sides are the same as sham.

that KYC reduces apoptosis in the brains of MCAO mice. Collectively, our studies suggest that MPO-mediated oxidative stress is a crucial factor in increasing inflammation and apoptosis in stroke.

KYC Reduced the Oxidation and Apoptosis of Neurons in the Brains of MCAO Mice. To investigate how MPO-generated oxidants damage neurons in MCAO, we colocalized neurons (red) with ClTyr (green) (Fig. 4A), a specific biomarker for MPO-mediated oxidation, and with $\mathrm{NO}_{2} \mathrm{Tyr}$ (green) (Fig. 4B), a biomarker for MPO-mediated nitration reaction in the brain cortex ischemic core of mice 3 days after MCAO. We found that both MPO-dependent oxidative products were colocalized with some of the neurons in the brain cortex ischemic core of PBS-treated MCAO mice. Moreover, KYC treatment significantly reduced neuron loss $(n=5, P<0.01$; Fig. 4D) and the chlorination and nitration in neurons in the brain cortex ischemic core of MCAO mice $(n=5, P<0.05$; Fig. 4, E and F). Neuron apoptotic death was also noticeably increased in the brain cortex ischemic core of MCAO mice (Fig. 4C). KYC markedly reduced the percentage of neurons undergoing apoptosis in MCAO mice ( $n=5, P<0.01$; Fig. 4G).

KYC Treatment Protected the Conserved Wnt/ $\beta$-Catenin Pathway in the Brains of MCAO Mice. A recent publication showed that treating MCAO mice with 4-aminobenzoic acid hydrazide increases neurogenesis (Kim et al., 2016). As KYC treatment also accelerated the recovery

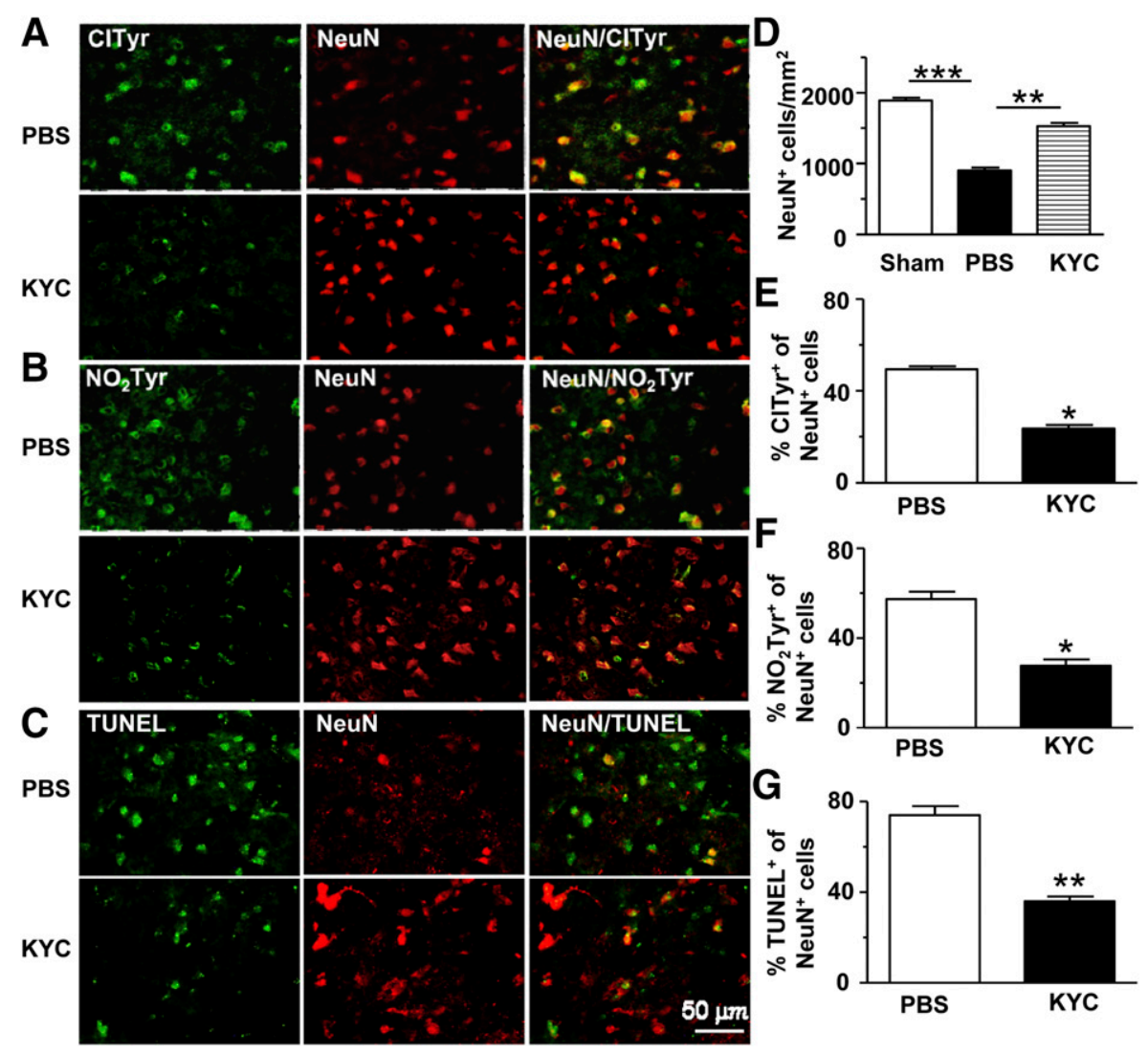

Fig. 4. MPO induces neuronal injury in the cortex ischemic core of mice 3 days after MCAO. (A) Colocalization of ClTyr and neurons in MCAO brains. (B) Colocalization of $\mathrm{NO}_{2} \mathrm{Tyr}$ and neurons in MCAO brains. (C) Colocalization of TUNEL ${ }^{+}$cells and neurons in MCAO brains. Green: ClTyr, $\mathrm{NO}_{2} \mathrm{Tyr}$, or TUNEL; red: neuronal nuclei (NeuN); yellow: NeuN + ClTyr, $\mathrm{NO}_{2}$ Tyr, or TUNEL. (D) The changes in neuron density (cells $/ \mathrm{mm}^{2}$ ) after KYC treatment (one-way analysis of variance with Bonferroni's test, $* * P<$ $0.01 ; * * * P<0.001$ ). (E) The percentage of $\mathrm{ClTyr}^{+} / \mathrm{NeuN}^{+}$cells in total $\mathrm{NeuN}^{+}$cells. (F) The percentage of $\mathrm{NO}_{2} \mathrm{Tyr}^{+} / \mathrm{NeuN}^{+}$cells in total NeuN $^{+}$cells. (G) The percentage of neurons that undergo apoptosis. Mann-Whitney test, $* P<$ $0.05 ; * * P<0.01$. All images and data were $n=5$. 

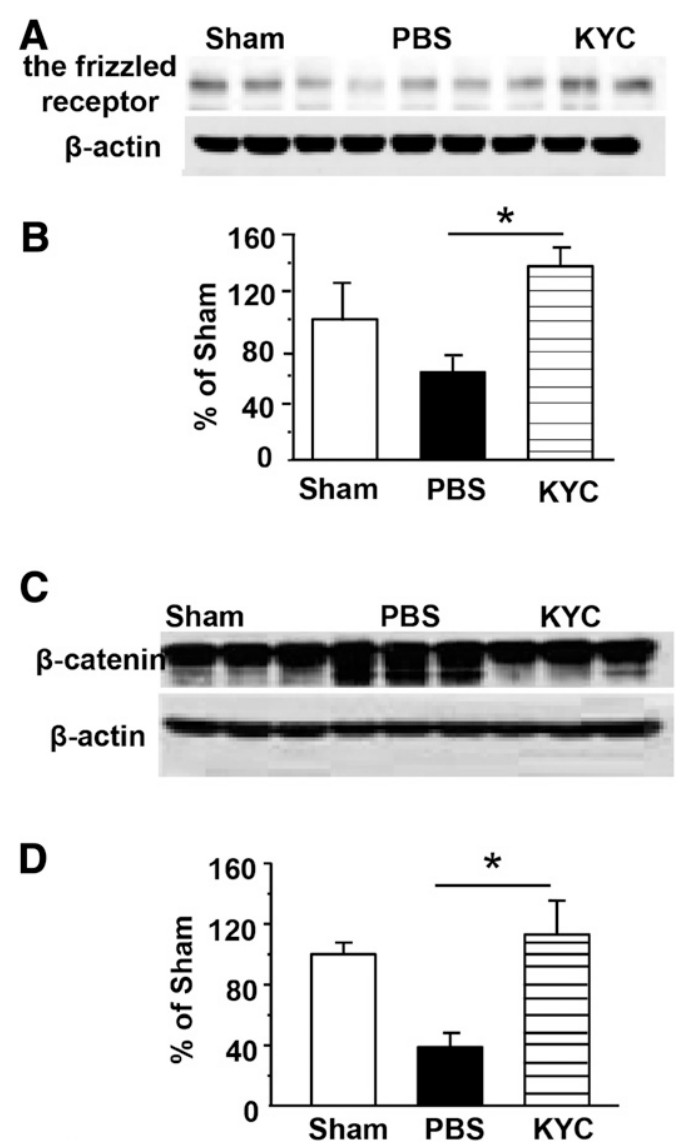

Fig. 5. The effect of KYC on the Wnt $/ \beta$-catenin signaling pathway in MCAO mice. Mice were treated with KYC $(10 \mathrm{mg} / \mathrm{kg} / \mathrm{d}$, i.p. $)$ starting at 1 hour after MCAO. After 3 days, the ischemic brain hemisphere of MCAO mice was harvested and proteins were extracted. Western blots were performed as described in Materials and Methods. (A) Western blots of the frizzled receptor and loading control ( $\beta$-actin). (B) Density analyses of (A). (C) Western blots of $\beta$-catenin and the loading control ( $\beta$-actin). (D) Density analyses of $(\mathrm{C})$. The density analyses were performed using ImageJ (NIH). The data are the density of proteins/density of $\beta$-actin. The density data for sham groups were normalized to $100 \%$. $n=3$ group, Student's $t$ test, $* P<0.05$.

of neurologic function (the decrease of neurologic severity scores) in MCAO mice (Yu et al., 2016) (Fig. 1A), we investigated whether KYC treatment can also increase neurogenesis in MCAO mice. The conserved $\mathrm{Wnt} / \beta$-catenin pathway regulates stem cell pluripotency and cell differentiation (MacDonald et al., 2009), which is critical for inducing neurogenesis in the central nervous system (Daneman et al., 2009; Sun et al., 2014). We determined two important components of this pathway, the frizzled receptor and $\beta$-catenin, in the brain ischemic hemisphere of mice 3 days after MCAO. Western blot analysis showed that frizzled receptor was notably reduced in the brains of MCAO mice compared with sham controls $(\sim 50 \%$, $n=3$; Fig. 5, A and B). KYC treatment significantly increased frizzled receptor expression in the brains of MCAO mice $(n=$ $3, P<0.05$; Fig. 5, A and B). MCAO also markedly increased the degradation of $\beta$-catenin (Fig. $5 \mathrm{C}$ ) and reduced the levels of $\beta$-catenin $(\# \times 223 \mathrm{c} 90 \mathrm{kD})$ in the brains of mice 3 days after MCAO (40\% compared with sham controls, $n=3$; Fig. 5, C and D). KYC significantly reduced the degradation and increased the expression of $\beta$-catenin ( $n=3$ /group, $P<0.05$; Fig. $5, \mathrm{C}$ and D).

KYC Increased the Number of NSCs in the Brains of Mice after MCAO. Next, we investigated the effects of KYC on the survival of NSCs in MCAO mice. First, we determined the changes of SOX2, a transcription factor that maintains NSCs (Episkopou, 2005; Pevny and Nicolis, 2010), in the brain cortex ischemic penumbra of MCAO mice. Compared with sham-operation mice, immunofluorescence studies showed that MCAO increased SOX2 ${ }^{+}$cells (Fig. 6, B and D) in the brain cortex ischemic penumbra of the mice 7 days after MCAO ( $n=5, P<0.001$; Fig. $6 \mathrm{~F}$ ) compared with the sham group (Fig. 6A). However, KYC treatment further increased the number of SOX ${ }^{+}$cells (KYC vs. PBS, $n=5, P<0.05$; Fig. $6, \mathrm{C}, \mathrm{E}$, and $\mathrm{F}$ ). KYC treatment also increased the number of $\mathrm{SOX}^{+}$cells in the brain cortex ischemic penumbra of mice 21 days after MCAO ( $n=5, P<0.05$ ) (Fig. 6F). To further strengthen these findings, we determined changes in Nestin, a marker for neuronal precursor cells (Wiese et al., 2004), in the brain cortex ischemic penumbra of mice 7 days after MCAO (Faiz et al., 2015) (Fig. 7). MCAO increased Nestin ${ }^{+}$cells in the ischemic penumbra of PBS-treated mice compared with the sham group (Fig. 7, A, B, and D). On the other hand, KYCtreated MCAO mice (Fig. 7, C and E) had significantly more Nestin $^{+}$cells than PBS-treated MCAO mice $(n=5, P<0.05$; Fig. 7F).

KYC Increased NSC Proliferation and Differentiation in the Brains of MCAO Mice. To understand how MPO-dependent oxidative stress affects NSC differentiation
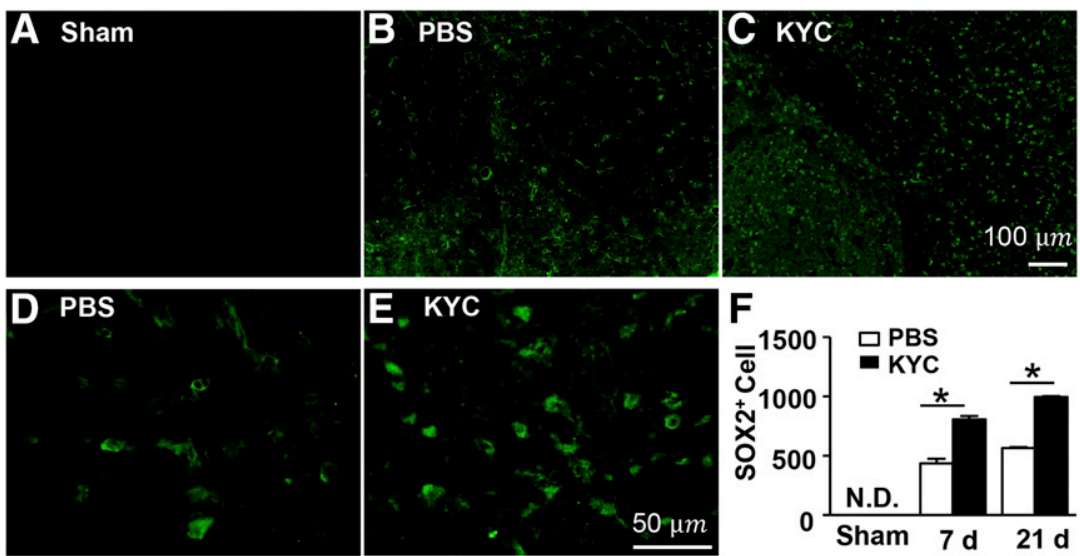

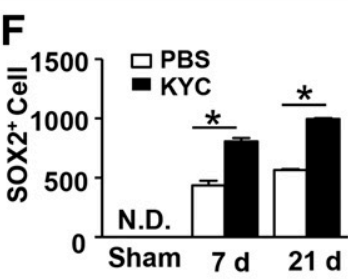

Fig. 6. KYC treatment increased the number of $\mathrm{SOX} 2^{+}$ NSCs in the brains of mice after MCAO. Mice were treated with KYC $(10 \mathrm{mg} / \mathrm{kg} / \mathrm{day}$, i.p.) starting 1 hour after MCAO. (A-E) Images of SOX2 ${ }^{+}$cells in brain cortex ischemic penumbra of mice 7 days after MCAO. (A-C) $10 \times$ images; (D and E) $40 \times$ images. (F) Cell counts of $\mathrm{SOX}^{+}$cells in the brain cortex ischemic penumbra of mice 7 and 21 days after MCAO. $n=5$ /group, one-way analysis of variance with Bonferroni's test, $* P<0.05$. N.D., none detected. 

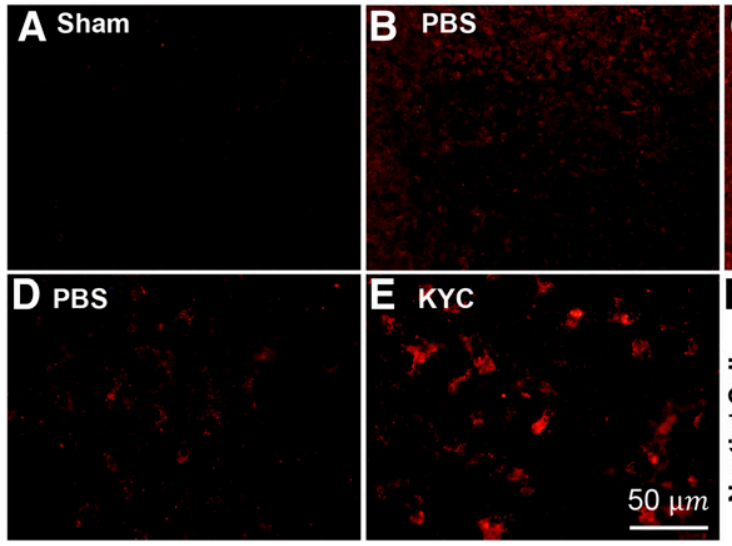

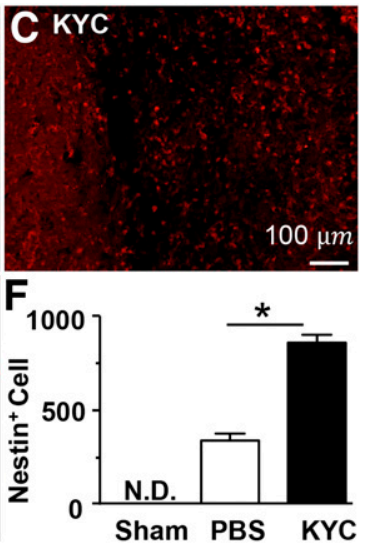

Fig. 7. KYC treatment increased the number of Nestin ${ }^{+}$ NSCs in the brains of mice after MCAO. Mice were treated with $\mathrm{KYC}(10 \mathrm{mg} / \mathrm{kg} /$ day, i.p. $)$ starting at 1 hour after MCAO. (A-E) Images of $\mathrm{Nestin}^{+}$cells in brain cortex ischemic penumbra of mice 7 days after MCAO. (A-C) $10 \times$ images; (D and E) $40 \times$ images. (F) Cell counts of Nestin $^{+}$cells in the brain cortex ischemic penumbra of mice 7 days after MCAO. $n=5$ /group, one-way analysis of variance with Bonferroni's test, $* P<0.05$. N.D., none detected.
(Wiese et al., 2004), we detected the changes of Ki67-positive cells for the proliferation of adult neurogenesis (Kee et al., 2002) and doublecortin (DCX) for immature neurons (differentiation) (Ardelt et al., 2013; Zhang et al., 2014). Figure 8 shows the changes of $\mathrm{Ki}^{+} 7^{+}$cells and $\mathrm{Dcx}^{+}$cells in the brain cortex ischemic penumbra of mice 7 days after MCAO. We found that MCAO alone increased $\mathrm{Ki}^{+} 7^{+}$cells in the brains of MCAO mice (Fig. 8A), but KYC treatment caused an additional 1.5-fold increase of $\mathrm{Ki}^{+} 7^{+}$cells in the brains of MCAO mice (PBS vs. KYC, $n=5, P<0.001$; Fig. $8 \mathrm{C}$ ). Dcx $^{+}$cells were also significantly increased in the brain cortex ischemic penumbra of mice 7 days after MCAO (Fig. 8B). KYC treatment also caused a 3 -fold increase of $\mathrm{Dcx}^{+}$cells in the brains of MCAO mice (PBS vs. KYC, $n=5, P<0.001$; Fig. 8D).

KYC Reduced Oxidative Injuries in NSCs in the Brains of MCAO Mice. To investigate if MPO-dependent oxidative stress directly damages NSCs in ischemic stroke, we colocalized MPO-mediated oxidation products with $\mathrm{SOX}^{+}$ cells in brain sections of MCAO mice. Figure 9A shows the images of immunofluorescent stains of ClTyr in the brain cortex ischemic penumbra of mice 7 days after MCAO. Image analysis results indicated that most of the $\mathrm{SOX} 2^{+}$cells were colocalized with ClTyr in PBS-treated MCAO mice, suggesting that most of the $\mathrm{SOX} 2^{+}$cells were oxidatively injured (Fig. 9A). In contrast, KYC-treated mice not only had more SOX2 ${ }^{+}$ cells, but most of them were free of ClTyr as well ( $n=5, P<$ 0.05; Fig. 9, A and C). We also colocalized another MPO oxidation product, $\mathrm{NO}_{2} \mathrm{Tyr}$, with $\mathrm{SOX} 2^{+}$cells in the brain cortex ischemic penumbra of mice 7 days after MCAO (Fig. 9, $\mathrm{B}$ and $\mathrm{D})$. In agreement with the ClTyr study, the percentage of $\mathrm{SOX}_{2}^{+}$cells that were colocalized with $\mathrm{NO}_{2} \mathrm{Tyr}$ were significantly higher for PBS-treated MCAO mice than for KYC-treated MCAO mice ( $n=5, P<0.05$; Fig. 9D).

KYC Decreased NSC Apoptosis in the Brains of MCAO Mice. To investigate the impact of MPO-dependent oxidative stress on survival of NSCs, we determined the apoptosis of $\mathrm{SOX}^{+}$cells in the brain cortex ischemic penumbra of PBS- or KYC-treated MCAO mice (Fig. 10). The TUNEL

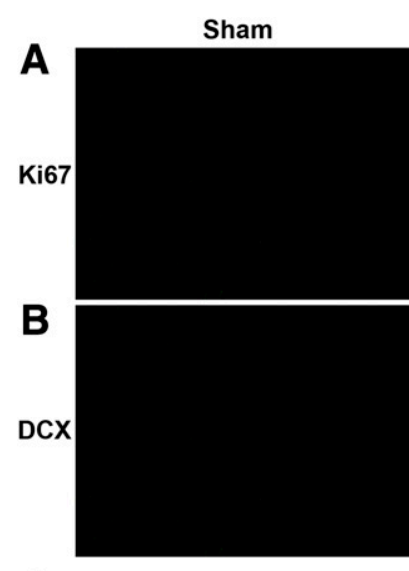

C

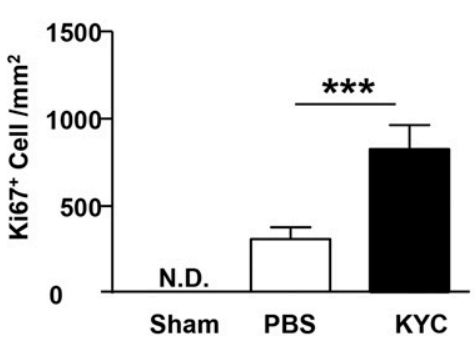

PBS
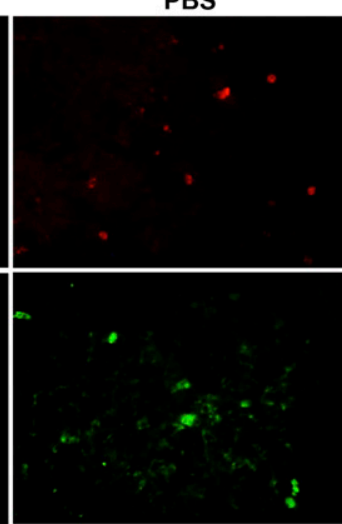

D

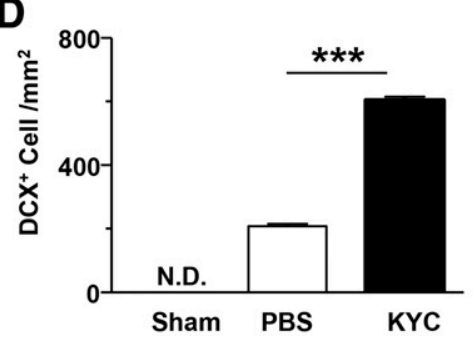

Fig. 8. KYC treatment increased the numbers of Ki $67^{+}$ cells and $\mathrm{DCX}^{+}$immature neurons in the brains of mice after MCAO. (A) Images of Ki67 ${ }^{+}$cells in the brain cortex ischemic penumbra of mice 7 days after MCAO. (B) Images of $\mathrm{DCX}^{+}$cells in the brain cortex ischemic penumbra of mice 7 days after MCAO. (C) Cell counts of Ki $67^{+}$cells. (D) Cell counts of $\mathrm{DCX}^{+}$cells. $n=5 /$ group, $*_{* *} P<0.001$, one-way analysis of variance with Bonferroni's test. N.D., none detected. 


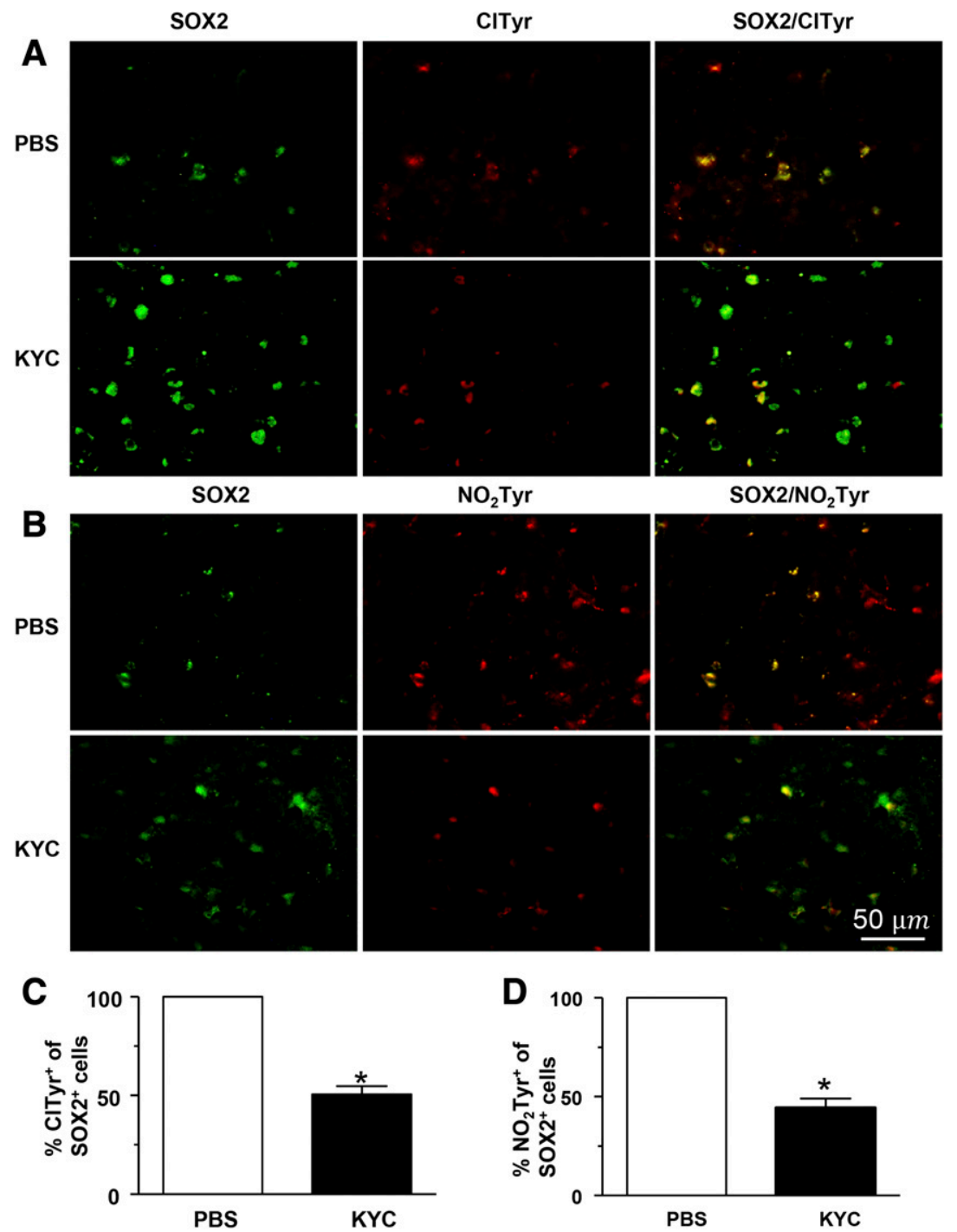

Fig. 9. MPO-dependent oxidative injury in $\mathrm{SOX}^{+}$cells in mice 7 days after MCAO. (A) KYC inhibited ClTyr formation in $\mathrm{SOX}_{2}{ }^{+} \mathrm{NSCs}$ in the brain cortex ischemic penumbra of MCAO mice. (B) KYC inhibited $\mathrm{NO}_{2} \mathrm{Tyr}$ formation in SOX2 ${ }^{+}$NSCs. Green: SOX2; red: ClTyr or $\mathrm{NO}_{2}$ Tyr; yellow: SOX2 + ClTyr or SOX2 + $\mathrm{NO}_{2}$ Tyr. (C) The percentage of $\mathrm{ClTyr}^{+} / \mathrm{SOX}^{+}$cells in total $\mathrm{SOX}^{+}$ cells. (D) The percentage of $\mathrm{NO}_{2} \mathrm{Tyr}^{+} / \mathrm{SOX}^{+}$cells in total $\mathrm{SOX}^{+}$cells. ${ }^{*} P<0.05, \mathrm{KYC}$ vs. PBS, Mann-Whitney test, $n=5$ /group

assay showed that most of the $\mathrm{SOX}^{+}$cells in PBS-treated MCAO mice were TUNEL-positive (>80\%) (Fig. 10A). KYC treatment significantly increased the number of SOX2 ${ }^{+}$cells but reduced the number of $\mathrm{TUNEL}^{+}$cells (Fig. 10A). As a consequence, the percentage of $\mathrm{SOX}^{+} / \mathrm{TUNEL}^{+}$cells of total $\mathrm{SOX}^{+}$cells was noticeably decreased $(n=5, P<0.05$; Fig. 10B).

KYC Protected Exogenous NSCs in the Brains of MCAO Mice. Finally, we performed NSC transplantation experiments to evaluate if KYC also protects exogenous NSCs in the brains of MCAO mice. We injected GFP-labeled NSCs into mice 1 day after MCAO. After NSC transplantation, mice were treated with PBS or KYC (10 mg/kg/day) for 2 weeks. Then, the brains were removed, and the effects of KYC on exogenous NSC survival and differentiation were evaluated. Figure 11A shows GFP-labeled cells in brain striatum ischemic penumbra of mice 2 weeks after NSC transplantation. Without GFP-NSC transplantation, no green fluorescence was detected in mice (control). GFP-labeled cells were detected in both transplantation groups. However, KYC-treated MCAO

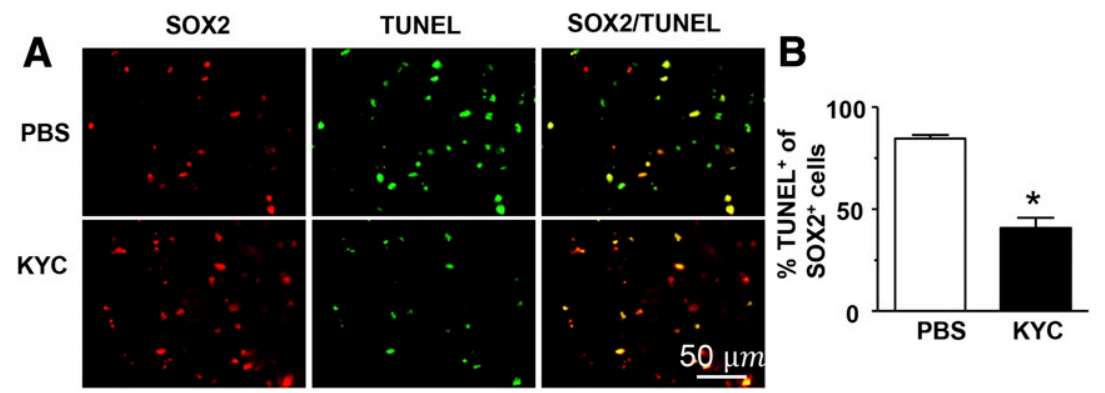

Fig. 10. KYC decreased SOX2 ${ }^{+} \mathrm{NSC}$ apoptosis in the brains of mice after MCAO. (A) Image of $\mathrm{SOX}^{+}$and TUNEL $^{+}$cells in the brain cortex ischemic penumbra of mice 7 days after MCAO. Green: TUNEL; red: SOX2; yellow: SOX2 + TUNEL. (B) The percentage of SOX2 ${ }^{+}$ cells that undergo apoptosis. $* P<0.05$, KYC vs. PBS, Mann-Whitney test, $n=5$ /group. 


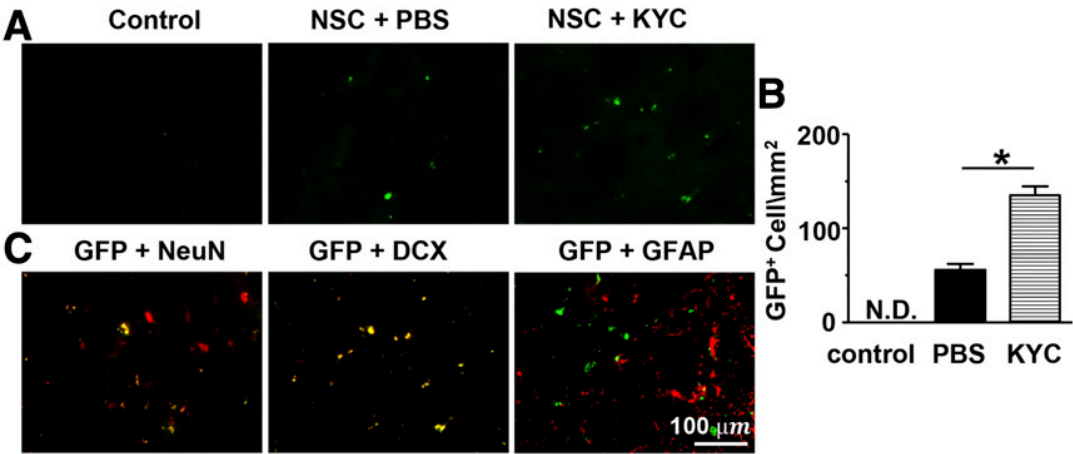

Fig. 11. KYC increased efficiency of exogenous NSC transplantation in the brains of mice after MCAO. (A) Images of GFP-labeled cells in the brain striatum ischemic penumbra of mice 14 days after MCAO. (B) The cell counts of GFP-labeled cells in the brain striatum ischemic penumbra of MCAO mice. $n=4$ /group, one-way analysis of variance-Bonferroni's test, $* P<0.05$. (C) Colocalization of GFP-labeled cells with the DCX, neuronal nuclei (NeuN), and Glial fibrillary acidic protein (GFAP).

mice had more GFP-labeled NSCs than PBS-treated mice ( $n=$ $4, P<0.05$; Fig. 11B). Moreover, we found that GFP-labeled cells were colocalized with DCX and neuronal nuclei antibodies (Fig. 11C), suggesting that transplanted GFP-NSCs have survived and differentiated into neurons or immature neurons. On the other hand, we did not detect the colocalization of GFP and Glial fibrillary acidic protein (Fig. 11C), the marker for astrocytes.

\section{Discussion}

It is well known that inflammation and oxidative stress play detrimental roles in ischemic stroke, especially during reperfusion. Infiltrated neutrophils and activated microglia produce a large number of free radicals and oxidants to injure central nervous system tissue, which leads to long-term disabilities and death in stroke patients (Roger et al., 2012). We have reported (Yu et al., 2016) that inhibition of MPO activity 3 days after reperfusion reduced MPO-mediated oxidative stress, which led to decreased neurologic severity scores, infarct size, myeloid cell infiltration and activation, and blood-brain barrier leakage in MCAO mice. Thus, MPO, mainly expressed in neutrophil and microglia, plays a causal role in reperfusion injury in stroke.

To understand the mechanisms of MPO-mediated brain injury in stroke, we investigated the impact of MPO-mediated oxidative stress on inflammation, neuronal damage, and neuroregeneration in the brains of MCAO mice. We show that inhibition of MPO in MCAO greatly decreased neurologic deficit and brain atrophy. Moreover, KYC treatment started 48 hours after reperfusion still markedly decreased disease severity, suggesting that KYC has a sufficiently wide therapeutic window. Our data indicate that inhibition of MPO is an effective strategy for reducing brain damage in stroke patients. Treatment with KYC also decreased proinflammatory myeloid cells and the expression of HMGB1, RAGE, and $\mathrm{NF}-\kappa \mathrm{B}$ p50 in the brains of MCAO mice, which implies the direct involvement of MPO in the increase of inflammation and apoptosis in the brains of MCAO mice. Finally, we showed that both neurons and NSCs are oxidatively injured by MPOdependent oxidation. KYC treatment significantly increased the survival of both neurons and NSCs in the brains of MCAO mice. More importantly, our studies suggest that KYC treatment protected NSC proliferation and differentiation, resulting in the increase of both endogenous and exogenous cell replacement in the brains of MCAO mice. Taken together, our study suggests that MPO-dependent oxidative stress directly participates in brain tissue injury at multiple levels during stroke and could be a major driving force for oxidative injury in MCAO mice. MPO should be a good therapeutic target for the treatment of stroke.

It has been found that microglia/macrophage polarization plays an important role in a patient's recovery from neuroinflammation diseases (Hu et al., 2015; Xiong et al., 2016). It is known that M1 proinflammatory macrophages and microglial cells produce a large amount of oxidative stress and inflammatory mediators that could damage brain tissue after stroke. On the other hand, macrophages and microglial cells could also be polarized to a M2 phenotype that participates in inflammation resolution and tissue repair. Recent studies have shown that M1/M2 microglia/macrophage polarization also plays a significant role in brain injury and tissue repair after stroke (Hu et al., 2012). Several studies found that drugs which downregulate M1 macrophage/microglia and/or upregulate M2 macrophage/microglia polarization are beneficial for MCAO mice to recover from ischemic/reperfusion injury (Jin et al., 2014; Xie et al., 2014). Previously, we have reported that KYC treatment significantly decreased the number of $\mathrm{Iba}^{+}$cells in the brains of MCAO mice (Yu et al., 2016). Our new data indicate that inhibition of MPO activity by KYC only noticeably reduced the number of $\mathrm{M} 1$ proinflammatory microglial cells but had no impact on M2 microglia. Our results suggest that MPO-dependent oxidative stress participates in M1 microglia activation but not M1/M2 polarization in MCAO mice. It has been reported that the increase of $\mathrm{N} 2$ neutrophils in MCAO brains increases neutrophil clearance, which should benefit the resolution of inflammation (Cuartero et al., 2013). Our study showed that KYC treatment only reduced N1 neutrophils but had no effect on the number of N2 neutrophils in the brains of MCAO mice, which indicates that MPOmediated oxidation only modulates $\mathrm{N} 1$ neutrophil activation. Therefore, targeting MPO activity should significantly minimize proinflammatory myeloid cell-induced brain injury in stroke.

The HMGB1/RAGE/NF- $\kappa$ B signaling pathway is considered one of the key regulators of inflammation and apoptosis in stroke (Singh et al., 2016). Macrophage and microglia can actively release HMGB1 during inflammation. Necrotic or damaged cells also release HMGB1. Extracellular HMGB1 binds to cell surface receptors, such as RAGE, which activates the NF- $\kappa \mathrm{B}$ pathway. As a consequence, activation of the HMGB1/RAGE/NF- $\kappa$ B pathway increases the expression of a wide variety of inflammatory mediators, escalates the acute inflammatory response, and increases apoptosis in vivo (Gangemi et al., 2015). It is also known that the HMGB1/RAGE/NF- $\kappa$ B pathway could be regulated by oxidative stress 
(Yu et al., 2015). It has been reported that the expression of HMGB1, RAGE, and NF- $\kappa$ B is upregulated in stroke, which leads to the increase of inflammation and apoptosis in stroke (Qiu et al., 2008). We found that blocking MPO activity is sufficient for reducing the expression of HMGB1, RAGE, and $\mathrm{NF}-\kappa \mathrm{B}$ p50 in the brains of MCAO mice. Our data suggest that MPO-dependent oxidative stress is an upstream event of the HMGB1/RAGE/NF- $\kappa$ B pathway and plays a major role in activation of this signaling pathway.

We showed that MCAO significantly increased neuron loss in the brains of MCAO mice. KYC markedly reduced neuron loss induced by MCAO, suggesting that MPO-mediated oxidative stress plays an important role in damaging neuronal function in stroke (Yu et al., 2016). To date, no neuroprotective agents have been approved by the Food and Drug Administration for stroke patients (Chen et al., 2011; Grupke et al., 2015). Although ischemic/reperfusion injury increases the number of NSCs in the brains of MCAO mice (Kernie and Parent, 2010; Lin et al., 2015), it appears to not be enough to stop disability. Clinical trials of stem cell replacement also failed to reduce neuronal injury in stroke patients (Trounson and McDonald, 2015). How to increase the effectiveness of endogenous and exogenous NSC replacement has become a major challenge in this field (Wang et al., 2017). Previous studies have shown that elevated levels of $\mathrm{H}_{2} \mathrm{O}_{2}$ and $\mathrm{NO}$ may be required for stimulating neurogenesis (Perez Estrada et al., 2014; Yuan et al., 2015). However, the oxidants generated by MPO are much more potent and toxic than $\mathrm{H}_{2} \mathrm{O}_{2}$. Accordingly, MPO oxidants should induce greater damage to neurogenesis (Mutsaers and Tofighi, 2012; Xiao et al., 2014). A recent publication has shown that inhibition of MPO increased neurogenesis in MCAO mice (Kim et al., 2016). We also found that KYC significantly increased the number of NSCs, NSC proliferation, and NSC differentiation. We observed the colocalization of ClTyr and SOX2 ${ }^{+}$cells in PBS-treated MCAO mice, which suggests that MPO-mediated oxidants directly induce oxidative injury in NSCs. KYC treatment reduced not only the oxidative injury in NSCs, but NSC apoptosis as well. Thus, inhibition of MPO activity should be an effective strategy for increasing endogenous NSCs in stroke therapy. We confirmed our findings with GFP-labeled NSC transplantation experiments. We found that MCAO mice treated with KYC had a significantly higher number of GFP-labeled cells. Furthermore, GFP-labeled cells are colocalized with antibody against both immature and mature neurons in MCAO mice, suggesting that inhibition of MPO protects exogenous NSC survival and differentiation, which should be an effective strategy for increasing the efficiency of NSC transplantation.

Recent studies have suggested that MPO is expressed in activated microglia and astrocytes in neuroinflammatory and neurodegenerative diseases (Nagra et al., 1997; Green et al., 2004; Choi et al., 2005; Lefkowitz and Lefkowitz, 2008). Thus, MPO has been proposed as a drug target for such diseases to reduce oxidative stress and inflammation in brains. Our study demonstrated that inhibition of MPO reduced proinflammatory immune cells, inflammation, and oxidative injury, suggesting that MPO inhibitors (such as KYC) could be effective tools for treating neuroinflammatory diseases, i.e., brain ischemia. More importantly, inhibition of MPO protected both endogenous and exogenous neuroregeneration, indicating that MPO inhibitors could be used in regenerative medicine for increasing the efficiency of stem cell transplantation in neuroinflammatory and neurodegenerative diseases.

In conclusion, in this report, we provide new evidence showing that MPO-dependent oxidative stress induces extensive oxidative injury in stroke, which leads to increased inflammation, neuron/NSC oxidation and apoptosis, and decreased neurogenesis. Inhibition of MPO activity not only reduces stroke damage but increases neurogenesis as well, which should greatly benefit stroke patients.

\section{Authorship Contributions}

Participated in research design: Zhang, Yu.

Conducted experiments: Yu, Zheng, Liang.

Performed data analysis: Zhang, Yu.

Wrote or contributed to the writing of the manuscript: Zhang, Yu.

\section{References}

Allen CL and Bayraktutan U (2009) Oxidative stress and its role in the pathogenesis of ischaemic stroke. Int $J$ Stroke 4:461-470.

Ardelt AA, Bhattacharyya BJ, Belmadani A, Ren D, and Miller RJ (2013) Stromal derived growth factor-1 (CXCL12) modulates synaptic transmission to immature neurons during post-ischemic cerebral repair. Exp Neurol 248:246-253.

Arnhold J and Flemmig J (2010) Human myeloperoxidase in innate and acquired immunity. Arch Biochem Biophys 500:92-106.

Barone FC, Hillegass LM, Tzimas MN, Schmidt DB, Foley JJ, White RF, Price WJ, Feuerstein GZ, Clark RK, Griswold DE, et al. (1995) Time-related changes in myeloperoxidase activity and leukotriene B4 receptor binding reflect leukocyte influx in cerebral focal stroke. Mol Chem Neuropathol 24:13-30.

Becker KJ, Kindrick DL, Lester MP, Shea C, and Ye ZC (2005) Sensitization to brain antigens after stroke is augmented by lipopolysaccharide. J Cereb Blood Flow Metab 25:1634-1644.

Bennett ML, Bennett FC, Liddelow SA, Ajami B, Zamanian JL, Fernhoff NB, Mulinyawe SB, Bohlen CJ, Adil A, Tucker A, et al. (2016) New tools for studying microglia in the mouse and human CNS. Proc Natl Acad Sci USA 113: E1738-E1746.

Bolokadze N, Lobjanidze I, Momtselidze N, Solomonia R, Shakarishvili R, and McHedlishvili G (2004) Blood rheological properties and lipid peroxidation in cerebral and systemic circulation of neurocritical patients. Clin Hemorheol Microcirc 30:99-105.

Bowie A and O'Neill LA (2000) Oxidative stress and nuclear factor-kappaB activation: a reassessment of the evidence in the light of recent discoveries. Biochem Pharmacol 59:13-23.

Breckwoldt MO, Chen JW, Stangenberg L, Aikawa E, Rodriguez E, Qiu S, Moskowitz MA, and Weissleder R (2008) Tracking the inflammatory response in stroke in vivo by sensing the enzyme myeloperoxidase. Proc Natl Acad Sci USA 105: 18584-18589.

Chalouhi N, Jabbour P, Magnotta V, and Hasan D (2014) Molecular imaging of cerebrovascular lesions. Transl Stroke Res 5:260-268.

Chen H, Song YS, and Chan PH (2009) Inhibition of NADPH oxidase is neuroprotective after ischemia-reperfusion. J Cereb Blood Flow Metab 29:1262-1272.

Chen H, Yoshioka H, Kim GS, Jung JE, Okami N, Sakata H, Maier CM, Narasimhan P, Goeders CE, and Chan PH (2011) Oxidative stress in ischemic brain damage: mechanisms of cell death and potential molecular targets for neuroprotection. Antioxid Redox Signal 14:1505-1517.

Choi DK, Pennathur S, Perier C, Tieu K, Teismann P, Wu DC, Jackson-Lewis V, Vila M, Vonsattel JP, Heinecke JW, et al. (2005) Ablation of the inflammatory enzyme myeloperoxidase mitigates features of Parkinson's disease in mice. J Neurosci 25: 6594-6600.

Cojocaru IM, Cojocaru M, Iliescu I, Botnaru L, Gurban CV, Sfrijan F, and Tanasescu R (2010) Plasma myeloperoxidase levels in patients with acute ischemic stroke. Rom J Intern Med 48:101-104.

Cuartero MI, Ballesteros I, Moraga A, Nombela F, Vivancos J, Hamilton JA, Corbí AL, Lizasoain I, and Moro MA (2013) N2 neutrophils, novel players in brain inflammation after stroke: modulation by the PPARy agonist rosiglitazone. Stroke 44:3498-3508.

Daneman R, Agalliu D, Zhou L, Kuhnert F, Kuo CJ, and Barres BA (2009) Wnt/betacatenin signaling is required for CNS, but not non-CNS, angiogenesis. Proc Natl Acad Sci USA 106:641-646.

Davies MJ, Hawkins CL, Pattison DI, and Rees MD (2008) Mammalian heme peroxidases: from molecular mechanisms to health implications. Antioxid Redox Signal 10:1199-1234.

Davis SM and Pennypacker KR (2016) Targeting antioxidant enzyme expression as a therapeutic strategy for ischemic stroke. Neurochem Int.107:23-32.

Domínguez C, Delgado P, Vilches A, Martín-Gallán P, Ribó M, Santamarina E, Molina C, Corbeto N, Rodríguez-Sureda V, Rosell A, et al. (2010) Oxidative stress after thrombolysis-induced reperfusion in human stroke. Stroke 41:653-660.

Donegà M, Giusto E, Cossetti C, Schaeffer J, and Pluchino S (2014) Systemic injection of neural stem/progenitor cells in mice with chronic EAE. J Vis Exp (86).

El Kossi MM and Zakhary MM (2000) Oxidative stress in the context of acute cerebrovascular stroke. Stroke 31:1889-1892.

Episkopou V (2005) SOX2 functions in adult neural stem cells. Trends Neurosci 28: 219-221. 
Faiz M, Sachewsky N, Gascón S, Bang KW, Morshead CM, and Nagy A (2015) Adult neural stem cells from the subventricular zone give rise to reactive astrocytes in the cortex after stroke. Cell Stem Cell 17:624-634.

Forghani R, Kim HJ, Wojtkiewicz GR, Bure L, Wu Y, Hayase M, Wei Y, Zheng Y, Moskowitz MA, and Chen JW (2015) Myeloperoxidase propagates damage and is a potential therapeutic target for subacute stroke. J Cereb Blood Flow Metab 35 485-493.

Fukuyama N, Takizawa S, Ishida H, Hoshiai K, Shinohara Y, and Nakazawa H (1998) Peroxynitrite formation in focal cerebral ischemia-reperfusion in rats occurs predominantly in the peri-infarct region. J Cereb Blood Flow Metab 18:123-129.

Gangemi S, Casciaro M, Trapani G, Quartuccio S, Navarra M, Pioggia G, and Imbalzano E (2015) Association between HMGB1 and COPD: a systematic review. Mediators Inflamm 2015:164913.

Green PS, Mendez AJ, Jacob JS, Crowley JR, Growdon W, Hyman BT, and Heinecke JW (2004) Neuronal expression of myeloperoxidase is increased in Alzheimer's disease. $J$ Neurochem 90:724-733.

Grupke S, Hall J, Dobbs M, Bix GJ, and Fraser JF (2015) Understanding history, and not repeating it. Neuroprotection for acute ischemic stroke: from review to preview. Clin Neurol Neurosurg 129:1-9.

Hu X, Leak RK, Shi Y, Suenaga J, Gao Y, Zheng P, and Chen J (2015) Microglial and macrophage polarization-new prospects for brain repair. Nat Rev Neurol 11: 56-64.

Hu X, Li P, Guo Y, Wang H, Leak RK, Chen S, Gao Y, and Chen J (2012) Microglia/macrophage polarization dynamics reveal novel mechanism of injury expansion after focal cerebral ischemia. Stroke 43:3063-3070.

Hurn PD and Macrae IM (2000) Estrogen as a neuroprotectant in stroke. J Cereb Blood Flow Metab 20:631-652.

Isobe C, Abe T, and Terayama Y (2009) Remarkable increase in 3-nitrotyrosine in the cerebrospinal fluid in patients with lacunar stroke. Brain Res 1305:132-136.

Jin Q, Cheng J, Liu Y, Wu J, Wang X, Wei S, Zhou X, Qin Z, Jia J, and Zhen X (2014) Improvement of functional recovery by chronic metformin treatment is associated with enhanced alternative activation of microglia/macrophages and increased angiogenesis and neurogenesis following experimental stroke. Brain Behav Immun 40:131-142.

Kee N, Sivalingam S, Boonstra R, and Wojtowicz JM (2002) The utility of Ki-67 and BrdU as proliferative markers of adult neurogenesis. $J$ Neurosci Methods 115 97-105.

Kernie SG and Parent JM (2010) Forebrain neurogenesis after focal Ischemic and traumatic brain injury. Neurobiol Dis 37:267-274.

Kim H, Wei Y, Lee JY, Wu Y, Zheng Y, Moskowitz MA, and Chen JW (2016) Myeloperoxidase inhibition increases neurogenesis after ischemic stroke. J Pharmacol Exp Ther 359:262-272.

Lefkowitz DL and Lefkowitz SS (2008) Microglia and myeloperoxidase: a deadly partnership in neurodegenerative disease. Free Radic Biol Med 45:726-731.

Li Y, Chopp M, Chen J, Wang L, Gautam SC, Xu YX, and Zhang Z (2000) Intrastriatal transplantation of bone marrow nonhematopoietic cells improves functional recovery after stroke in adult mice. J Cereb Blood Flow Metab 20:1311-1319.

Lin R, Cai J, Nathan C, Wei X, Schleidt S, Rosenwasser R, and Iacovitti L (2015) Neurogenesis is enhanced by stroke in multiple new stem cell niches along the ventricular system at sites of high BBB permeability. Neurobiol Dis 74:229-239.

MacDonald BT, Tamai K, and He X (2009) Wnt/beta-catenin signaling: components, mechanisms, and diseases. Dev Cell 17.9-26.

Manzanero S, Santro T, and Arumugam TV (2013) Neuronal oxidative stress in acute ischemic stroke: sources and contribution to cell injury. Neurochem Int 62:712-718.

Mutsaers HA and Tofighi R (2012) Dexamethasone enhances oxidative stressinduced cell death in murine neural stem cells. Neurotox Res 22:127-137.

Nagayama T, Lan J, Henshall DC, Chen D, O'Horo C, Simon RP, and Chen J (2000) Induction of oxidative DNA damage in the peri-infarct region after permanent focal cerebral ischemia. J Neurochem 75:1716-1728.

Nagra RM, Becher B, Tourtellotte WW, Antel JP, Gold D, Paladino T, Smith RA Nelson JR, and Reynolds WF (1997) Immunohistochemical and genetic evidence of myeloperoxidase involvement in multiple sclerosis. J Neuroimmunol 78:97-107.

Nour M, Scalzo F, and Liebeskind DS (2013) Ischemia-reperfusion injury in stroke. Intervent Neurol 1:185-199.

Pan B, Wang W, Zhong P, Blankman JL, Cravatt BF, and Liu QS (2011) Alterations of endocannabinoid signaling, synaptic plasticity, learning, and memory in monoacylglycerol lipase knock-out mice. J Neurosci 31:13420-13430.

Pérez Estrada C, Covacu R, Sankavaram SR, Svensson M, and Brundin L (2014) Oxidative stress increases neurogenesis and oligodendrogenesis in adult neural progenitor cells. Stem Cells Dev 23:2311-2327.

Pevny LH and Nicolis SK (2010) Sox2 roles in neural stem cells. Int J Biochem Cell Biol 42:421-424.

Qiu J, Nishimura M, Wang Y, Sims JR, Qiu S, Savitz SI, Salomone S, and Moskowitz MA (2008) Early release of HMGB-1 from neurons after the onset of brain ischemia. J Cereb Blood Flow Metab 28:927-938.
Re G, Azzimondi G, Lanzarini C, Bassein L, Vaona I, and Guarnieri C (1997) Plasma lipoperoxidative markers in ischaemic stroke suggest brain embolism. Eur $J$ Emerg Med 4:5-9.

Roger VL, Go AS, Lloyd-Jones DM, Benjamin EJ, Berry JD, Borden WB, Bravata DM, Dai S, Ford ES, Fox CS, et al.; American Heart Association Statistics Committee and Stroke Statistics Subcommittee (2012) Heart disease and stroke statistics-2012 update: a report from the American Heart Association. Circulation 125:e2-e220.

Shoamanesh A, Preis SR, Beiser AS, Vasan RS, Benjamin EJ, Kase CS, Wolf PA DeCarli C, Romero JR, and Seshadri S (2015) Inflammatory biomarkers, cerebra microbleeds, and small vessel disease: Framingham Heart Study. Neurology 84: $825-832$.

Singh V, Roth S, Veltkamp R, and Liesz A (2016) HMGB1 as a key mediator of immune mechanisms in ischemic stroke. Antioxid Redox Signal 24:635-651.

Sun FL, Wang W, Zuo W, Xue JL, Xu JD, Ai HX, Zhang L, Wang XM, and Ji XM (2014) Promoting neurogenesis via Wnt/ $\beta$-catenin signaling pathway accounts for the neurorestorative effects of morroniside against cerebral ischemia injury. Eur $J$ Pharmacol 738:214-221.

Trounson A and McDonald C (2015) Stem cell therapies in clinical trials: progress and challenges. Cell Stem Cell 17:11-22.

van der Veen BS, de Winther MP, and Heeringa P (2009) Myeloperoxidase: molecular mechanisms of action and their relevance to human health and disease [published correction appears in Antioxid Redox Signal (2010) 12:322]. Antioxid Redox Signal 11:2899-2937.

Wang Y, Ji X, Leak RK, Chen F, and Cao G (2017) Stem cell therapies in age-related neurodegenerative diseases and stroke. Ageing Res Rev 34:39-50.

Weston RM, Jones NM, Jarrott B, and Callaway JK (2007) Inflammatory cell infiltration after endothelin-1-induced cerebral ischemia: histochemical and myeloperoxidase correlation with temporal changes in brain injury. J Cereb Blood Flow Metab 27:100-114.

Wiese C, Rolletschek A, Kania G, Blyszczuk P, Tarasov KV, Tarasova Y, Wersto RP, Boheler KR, and Wobus AM (2004) Nestin expression-a property of multi-lineage progenitor cells? Cellular and molecular life sciences. Cell Mol Life Sci 61: $2510-2522$

Wright CB, Moon Y, Paik MC, Brown TR, Rabbani L, Yoshita M, DeCarli C, Sacco R, and Elkind MS (2009) Inflammatory biomarkers of vascular risk as correlates of leukoariosis. Stroke 40:3466-3471.

Xiao Y, Li X, Cui Y, Zhang J, Liu L, Xie X, Hao H, He G, Kander MC, Chen M, et al. (2014) Hydrogen peroxide inhibits proliferation and endothelial differentiation of bone marrow stem cells partially via reactive oxygen species generation. Life Sci 112:33-40

Xie L, Sun F, Wang J, Mao X, Xie L, Yang SH, Su DM, Simpkins JW, Greenberg DA, and Jin K (2014) mTOR signaling inhibition modulates macrophage/microgliamediated neuroinflammation and secondary injury via regulatory $\mathrm{T}$ cells after focal ischemia. J Immunol 192:6009-6019.

Xiong XY, Liu L, and Yang QW (2016) Functions and mechanisms of microglia/macrophages in neuroinflammation and neurogenesis after stroke. Prog Neurobiol 142:23-44.

Yu G, Liang Y, Huang Z, Jones DW, Pritchard KA, Jr, and Zhang H (2016) Inhibition of myeloperoxidase oxidant production by $\mathrm{N}$-acetyl lysyltyrosylcysteine amide reduces brain damage in a murine model of stroke. J Neuroinflammation 13:119.

Yu Y, Tang D, and Kang R (2015) Oxidative stress-mediated HMGB1 biology. Front Physiol 6:93.

Yuan TF, Gu S, Shan C, Marchado S, and Arias-Carrión O (2015) Oxidative stress and adult neurogenesis. Stem Cell Rev 11:706-709.

Zhang H, Jing X, Shi Y, Xu H, Du J, Guan T, Weihrauch D, Jones DW, Wang W, Gourlay D, et al. (2013a) N-acetyl lysyltyrosylcysteine amide inhibits myeloperoxidase, a novel tripeptide inhibitor. J Lipid Res 54:3016-3029.

Zhang H, Ray A, Miller NM, Hartwig D, Pritchard KA, Jr, and Dittel BN (2015) Inhibition of myeloperoxidase at the peak of experimental autoimmune encephalomyelitis restores blood-brain-barrier integrity and ameliorates disease Severity. $J$ Neurochem [published ahead of print].

Zhang H, Xu H, Weihrauch D, Jones DW, Jing X, Shi Y, Gourlay D, Oldham KT, Hillery CA, and Pritchard KA, Jr (2013b) Inhibition of myeloperoxidase decreases vascular oxidative stress and increases vasodilatation in sickle cell disease mice. $J$ Lipid Res 54:3009-3015.

Zhang W, Cheng J, Vagnerova K, Ivashkova Y, Young J, Cornea A, Grafe MR, Murphy SJ, Hurn PD, and Brambrink AM (2014) Effects of androgens on early post-ischemic neurogenesis in mice. Transl Stroke Res 5:301-311.

Address correspondence to: Hao Zhang, Division of Pediatric Surgery, Department of Surgery, Medical College of Wisconsin, 8701 Watertown Plank Road, Milwaukee, WI 53226. E-mail: hzhang@mcw.edu 